Research Article

\title{
Comparison of unilateral spinal anaesthesia using low dose bupivacaine with or without fentanyl in lower limb surgery
}

\author{
Vinod S. Jaiswal $^{1}$, Devendra W. Thakare ${ }^{2}$
}

\author{
${ }^{1}$ Department of ICU and \\ Anaesthesia, Al rabha hospital, \\ Shahama, Abu Dhabi, UAE \\ ${ }^{2}$ Department of \\ Anaesthesiology, LTMMC and \\ LTMGH, Sion, Mumbai, India
}

Received: 20 July 2016

Accepted: 06 August 2016

*Correspondence to:

Dr. Vinod S. Jaiswal,

Email: drvinodjaiswal@ gmail.com

Copyright: (C) the author(s), publisher and licensee Medip Academy. This is an openaccess article distributed under the terms of the Creative Commons Attribution NonCommercial License, which permits unrestricted noncommercial use, distribution, and reproduction in any medium, provided the original work is properly cited.

\begin{abstract}
Background: Intrathecal opioids are synergistic with local anesthetics and intensifies sensory block without increasing motor block. This combination makes it possible to achieve spinal anesthesia without hemodynamic instability and adverse effects that are associated with higher doses of bupivacaine. Hence we conducted this comparative study using $5 \mathrm{mg}$ of hyperbaric bupivacaine with or without fentanyl $(25 \mu \mathrm{g})$ in unilateral spinal anaesthesia for lower limb surgery.
\end{abstract}

Methods: Sixty patients were randomized into two groups with Group B receiving $0.5 \%$ bupivacaine and Group BF receiving $0.5 \%$ bupivacaine $+25 \mu \mathrm{g}$ fentanyl intrathecal. Sensory and motor block quality and duration, post anesthesia care unit stay (PACU) and adverse effects were compared.

Results: The onset of sensory block $(6.17 \pm 1.44)$ was faster in Group B compared Group BF $(6.73 \pm 1.52)$ and duration of sensory blockade was intensified by addition of intrathecal fentanyl in Group BF. The onset and duration of motor blockade was similar in both the groups and was not affected by addition of fentanyl in Group BF. The number and mean duration stay in PACU was found to be significantly higher in patients 24 [80\%]; 30 minutes receiving fentanyl suggesting it prolonged duration of recovery. No patient in either group had hypotension, respiratory depression, sedation, nausea, vomiting, PDPH and TNS. Only 1 patient in each group experienced bradycardia and 4 patients in Group BF had mild pruritus.

Conclusions: Unilateral spinal anaesthesia with $5 \mathrm{mg}$ hyperbaric bupivacaine with $25 \mu \mathrm{g}$ fentanyl is a better choice than $5 \mathrm{mg}$ hyperbaric bupivacaine alone in short procedure of lower limb in orthopaedic surgery.

Keywords: Unilateral spinal anaesthesia, Bupivacaine, Intrathecal fentanyl, Lower limb surgeries

\section{INTRODUCTION}

Spinal anaesthesia is simple and reliable cost effective technique that has been widely used for ambulatory anaesthesia especially in orthopaedic patients with lower limb surgery. ${ }^{1}$ Spinal anaesthesia with lidocaine had been widely used for short duration surgeries over the years because of its short duration of action. But due to transient neurological symptoms (TNS) with lignocaine, spinal anaesthesia with bupivacaine is tried to provide anaesthesia for various outpatient surgeries. ${ }^{2-7}$ But use of large dose bupivacaine is associated with hemodynamic instability, delayed recovery of motor functions, urinary retention leading to need for prolonged observation of patient in postoperative recovery unit. ${ }^{8}$
These concerns have increased interest in use of small dose of bupivacaine for ambulatory anaesthesia.

For ambulatory surgical treatment of lower limbs unilateral spinal block procedure is thought to have more advantages over conventional spinal anaesthesia in producing extreme longer lasting block in the operative limb, reduction of hypotension, faster recovery and increased patient satisfaction. ${ }^{7-15}$

Low dose local anesthetic solutions by using a pencilpoint needle and slow intrathecal injection have been reported to obtain satisfactory unilateral spinal anesthesia (USpA), which should also minimize the cardiovascular effects of spinal block. ${ }^{13,16-19}$ With addition of lipophilic opioid to local anaesthetic, it is possible to improve the 
quality of anaesthesia even when low dose bupivacaine is administered. ${ }^{1,20-22}$

The purpose of the study was to compare the effectiveness of $5 \mathrm{mg}$ of hyperbaric bupivacaine with or without fentanyl $(25 \mu \mathrm{g})$ in unilateral spinal anaesthesia for lower limb surgery.

\section{METHODS}

After approval from ethical committee of institutional postgraduate review board of hospital and informed patient consent, 60 patients aged between18-65 years in ASA grade I, II, III undergoing elective as well as emergency lower limb orthopedic surgery with and without standard thigh tourniquet were included in this prospective, randomized, double blind, comparative study. Exclusion criteria were contraindications to spinal anaesthesia like hypersensitivity to local anaesthetics, deranged coagulation profile, mental disorders, ASA grade IV, potential airway problem, spine deformity, neurological diseases, patients receiving chronic analgesic therapy and inability to lie on operative side due to pain.

Preoperatively patients were evaluated for detailed clinical history, physical and systemic examination. Later patients were randomly divided into two groups each consisting 30 patients. Group B received $5 \mathrm{mg} 0.5 \%$ hyperbaric bupivacaine and Group BF received $5 \mathrm{mg}$ $0.5 \%$ hyperbaric bupivacaine and $25 \mu \mathrm{g}$ fentanyl. Patients after confirmation of adequate starvation were taken in the operation theater. They were monitored for vital signs like BP, pulse rate, respiratory rate and pulse oximeter and cardioscope monitor attached and switched on. A peripheral venous access was secured with $18 \mathrm{G}$ angiocath. No premedication was given. $500 \mathrm{ml}$ intravenous infusion of lactated Ringer's solution was given. Infusion was maintained at $4-8 \mathrm{ml} / \mathrm{kg} / \mathrm{hr}$ NS during intraoperative period.

Later the patients were placed in lateral decubitus position with the limb to be operated on in the dependent position. The vertebral column position was accurately visualized before dural puncture and was maintained as horizontal as possible by tilting the operating table or by putting a pillow under the shoulder. Dural puncture was performed at L3-4 interspace using 25-gauge Quinke's spinal needle with the midline approach and the needle hole was turned toward the dependent side. To ensure good needle placement gentle barbotage of $0.1 \mathrm{ml}$ was used. The drug was injected over 5 minutes slowly. The lateral decubitus position was maintained for 15 minutes from the beginning of the injection. Then patients were turned to supine position and no intraoperative sedation was given.

Hemodynamic variables were recorded every five minutes during the first 30 minutes after block placement and then every 15 minutes until the end of surgery. Any decrease in systolic arterial pressure (SAP) below 30\% of preoperative value was defined as hypotension and treated with a $200 \mathrm{ml}$ Ringer's lactate solution and if proved to be ineffective then $5 \mathrm{mg}$ ephedrine i.v. bolus was given. Bradycardia (defined as a heart rate under 45 beats/min) was treated with atropine $0.6 \mathrm{mg}$ i.v. If respiratory depression ( $\mathrm{RR}<8$ or $\mathrm{Spo} 2<90$ ) was observed then oxygen was administered with mask.

The sensory block was evaluated by using $20 \mathrm{G}$ hypodermic needle bilaterally after the end of injection. Dermatomal level tested every 2 min till level stabilized for four consecutive tests, then every five minutes till 30 minutes, then every 15 minutes until the point of regression of sensory level to L3 on the dependent side and the following data was noted. Onset of analgesia, highest level of dermatomal block on operated and nonoperated limb, time to reach this level from the time of injection on operated limb, time to two segment sensory regression, time for $\mathrm{L} 3$ segment sensory regression.

The motor block was evaluated using a Bromage Scale and the Bromage score of motor block at the time of reaching peak sensory level on operated and nonoperated limb, time to complete recovery of motor block and time to discharge from PACU or fast tracking was noted.

During surgery patients and surgeons satisfaction, side effects like pruritus, sedation if any were observed and noted. Post operatively duration of analgesia, time to transfer from post anaesthesia care unit (PACU) to ambulatory surgical unit (ASU), side effect like urinary retention if any were noted. Postoperative follow up was carried out on the day after surgery and one week after surgery by asking the patient about postoperative pain, post dural puncture headache and dysesthesia in the buttocks, thighs and lower limbs.

Statistical analysis was performed using Systat 7.0 (SPSS Inc, Chicago, IL). The two-sample student ' $t$ ' test was used to compare demographic data and times for readiness to surgery, block resolution. Ordinal data were analysed using the contingency table analysis with the Chi-square test. A p value $<0.05$ was considered significant. Unless otherwise indicated, continuous variables are presented as mean $\pm \mathrm{sd}$, while ordinal data are presented as number $(\%)$.

\section{RESULTS}

A total of 60 patients were included in the study and divided randomly into two groups $(n=30)$. Group B received $0.5 \%$ hyperbaric bupivacaine $5 \mathrm{mg}(1 \mathrm{ml})$ in $0.9 \%$ sterile preservative free normal saline $(0.5 \mathrm{ml})$. Group BF received $0.5 \%$ hyperbaric bupivacaine $5 \mathrm{mg}$ (1 $\mathrm{ml})$ and $25 \mu \mathrm{g}$ fentanyl $(0.5 \mathrm{ml})$.

Both groups were comparable with respect to age, weight, height, gender, ASA grades as given in Table 1. 
Table 1: Demographic characteristics of the patients during surgery.

\begin{tabular}{|lllll|}
\hline Parameters & & Group B & Group BF & p value \\
\hline Age (years) & & $35.9 \pm 12.13$ & $36.77 \pm 14.95$ & 0.806 \\
\hline Weight $(\mathrm{kg})$ & & $60.2 \pm 5.1$ & $59.3 \pm 5.15$ & 0.499 \\
\hline Height $(\mathrm{cm})$ & & $161.3 \pm 5.36$ & $158.53 \pm 6.29$ & 0.079 \\
\hline \multirow{2}{*}{ Sex } & Male & $24(80 \%)$ & $24(80 \%)$ & \multirow{2}{*}{1.000} \\
\cline { 2 - 4 } & Female & $6(20 \%)$ & $6(20 \%)$ & \multirow{2}{*}{0.114} \\
& I & $23(76.6 \%)$ & $21(70 \%)$ & \\
\cline { 2 - 5 } ASA Status & II & $05(16.7 \%)$ & $07(23.3 \%)$ & $02(6.7 \%)$ \\
& III & $02(6.7 \%)$ & & \\
\hline
\end{tabular}

The mean duration of surgery and application of tourniquet were comparable between the two groups and observed no significance among them as tabulated in Table 2.

Table 2: Duration of surgery and tourniquet application.

\begin{tabular}{|llll|}
\hline $\begin{array}{l}\text { Attributes } \\
\text { Duration of } \\
\text { surgery } \\
\text { (min) }\end{array}$ & $102.6 \pm 9.62$ & $102.87 \pm 9.97$ & 0.916 \\
\hline $\begin{array}{l}\text { Application } \\
\text { of } \\
\text { tourniquet }\end{array}$ & $15(50 \%)$ & $17(56.67 \%)$ & 0.128 \\
\hline
\end{tabular}

The onset of sensory block, median sensory level and the time to reach peak level was compared between the two groups in the operated limbs and the difference was not significant $(\mathrm{p}>0.05)$ as observed in Table 3. This suggests, intrathecal fentanyl does not affect onset of anaesthesia, the peak level achieved and time to reach peak level.

Table 3: Sensory block characteristics in the operated limb.

\begin{tabular}{|llll|}
\hline & Group B & Group BF & p value \\
\hline Onset(min) & $6.73 \pm 1.52$ & $6.17 \pm 1.44$ & 0.148 \\
\hline $\begin{array}{l}\text { Peak sensory } \\
\text { level }\end{array}$ & $\begin{array}{l}\mathrm{T}_{10} \\
\left(\mathrm{~T}_{8}-\mathrm{T}_{12}\right)\end{array}$ & $\begin{array}{l}\mathrm{T}_{10} \\
\left(\mathrm{~T}_{8}-\mathrm{T}_{12}\right)\end{array}$ & 0.741 \\
\hline $\begin{array}{l}\text { Time to reach } \\
\text { peak level } \\
\text { (min) }\end{array}$ & $15.83 \pm 2.4$ & $15.43 \pm 2.26$ & 0.511 \\
\hline
\end{tabular}

The statistically insignificant median peak sensory levels in the non-operated limb were observed in the two groups. Two patients in Group BF and one patient in Group B developed sensory block to L1. One patient in Group BF had T12 sensory level, so total four patients developed bilateral sensory blockade indicating unilateral sensory blockade was achieved only $98.33 \%$ in Group B and $95 \%$ in Group BF, which was comparable.
Table 4: Comparison of sensory level in non-operated limb.

\begin{tabular}{|lll|c|}
\hline & Group B & Group BF & p value \\
\hline $\begin{array}{l}\text { Peak } \\
\text { sensory }\end{array}$ & $\mathrm{L}_{3}$ & $\mathrm{~L}_{3}$ & \\
level & $\left(\mathrm{L}_{1}-\mathrm{L}_{5}\right)$ & $\left(\mathrm{T}_{12}-\mathrm{L}_{5}\right)$ & 0.718 \\
\hline
\end{tabular}

Time for 2 segment regression and time to L3 segment regression were compared in both the groups and found to be highly significant among the groups $(\mathrm{p}=0.000)$ and was given in Table 5.

Table 5: Comparison of time for 2 segment and L3 segment regression in operated limb.

\begin{tabular}{|llll|}
\hline Time in minutes & Group B & Group BF & $\begin{array}{l}\text { p } \\
\text { value }\end{array}$ \\
\hline $\begin{array}{l}\text { 2 segment } \\
\text { regression (min) }\end{array}$ & $61.9 \pm 6.33$ & $90.6 \pm 11.89$ & 0.000 \\
\hline $\begin{array}{l}\text { L3 segment } \\
\text { regression (min) }\end{array}$ & $128.0 \pm 5.12$ & $152.97 \pm 11.29$ & 0.000 \\
\hline
\end{tabular}

The motor blockade in the operated limb and in nonoperated limb for the two groups was assessed by Bromage score and the two groups were compared with each other and no statistical significance was obtained between them as given in Table 6 .

Time to complete recovery of motor blockade for operated limbs in both groups was also compared and found no significance between the two groups as in Table 7.

In our study, none of our patients developed failed block or required analgesic for inadequate block. All of them were satisfied with respect to anaesthesia. During surgery, surgeons found adequate muscle relaxation and were satisfied with the anaesthesia as presented in Table 8.

The incidence of complications and side effects before and after surgery were compared between the two groups and are arranged in Table 9. No patient in either group 
had hypotension, respiratory depression, sedation, nausea, vomiting, PDPH and TNS. Only 1 patient in each group experienced bradycardia and 4 patients in Group
BF had mild pruritus and treatment was given accordingly.

Table 6: Comparison of motor block in operated and non-operated limb.

\begin{tabular}{|c|c|c|c|c|c|c|c|}
\hline \multirow{2}{*}{\multicolumn{2}{|c|}{ Bromage Score }} & \multicolumn{2}{|c|}{ Operated side } & \multirow{2}{*}{ P value } & \multicolumn{2}{|c|}{ Non-operated side } & \multirow{2}{*}{ p value } \\
\hline & & Group B & Group BF & & Group B & Group BF & \\
\hline \multirow{2}{*}{$\mathbf{0}$} & Count & 0 & 0 & \multirow{8}{*}{0.257} & 23 & 28 & \multirow{8}{*}{0.71} \\
\hline & $\%$ within group & - & - & & $76.7 \%$ & $93.3 \%$ & \\
\hline \multirow{2}{*}{1} & Count & 3 & 2 & & 7 & 2 & \\
\hline & $\%$ within group & $9.9 \%$ & $6.6 \%$ & & $23.3 \%$ & $6.7 \%$ & \\
\hline \multirow{2}{*}{2} & Count & $7 *$ & 13 & & 0 & 0 & \\
\hline & $\%$ within group & $23.5 \%$ & $43.4 \%$ & & - & - & \\
\hline \multirow{2}{*}{3} & Count & $20 *$ & 15 & & 0 & 0 & \\
\hline & $\%$ within group & $66.6 \%$ & $50 \%$ & & - & - & \\
\hline
\end{tabular}

Table 7: Recovery of motor blockade in operated limb.

\begin{tabular}{|c|c|c|c|}
\hline & $\begin{array}{l}\text { Group B } \\
(n=30)\end{array}$ & $\begin{array}{l}\text { Group BF } \\
(n=30)\end{array}$ & p value \\
\hline $\begin{array}{l}\text { Time to } \\
\text { complete } \\
\text { recovery } \\
\text { (min) }\end{array}$ & $107 \pm 9.22$ & $109 \pm 6.38$ & 0.333 \\
\hline
\end{tabular}

Table 10 shows that fast tracking was done in 14(47\%) and 6(20\%) patients in Group B and Group BF respectively. The number of patients and mean duration of stay in PACU in the both groups was compared at different time intervals and the results found highly significant $(\mathrm{p}<0.001)$.

The mean duration of analgesia between the two groups were compared and found statistically highly significant with each other that were presented in Table 11.

\section{DISCUSSION}

Unilateral spinal anaesthesia is used when block is needed only on operative side. When surgery involves only one lower limb, such type of anaesthesia is advantageous and minimizes hemodynamic changes associated with conventional spinal anaesthesia. It also enables faster recovery, good cardiovascular stability and early discharge. ${ }^{24-26}$

For decades lidocaine has been the local anaesthetic of choice for spinal anaesthesia in the ambulatory surgical patient. But due to its permanent and transient neurologic toxicity, other avenues are being explored to achieve reliable spinal anaesthesia with rapid recovery and minimal adverse effects, that lead to exploration of adapting the longer acting spinal bupivacaine to ambulatory anaesthesia. ${ }^{7,21,27}$
Conventional large dose bupivacaine may delay the recovery of motor function, may cause urinary retention, hemodynamic instability, leading to delayed discharge. So the interest was increased to use small doses of bupivacaine with intrathecal fentanyl as it intensifies sensory blockade and its duration without increasing motor blockade or prolonging recovery. ${ }^{21}$

Fentanyl is a lipophilic opiod usually used as an adjunct to local anesthetics for enhancement of analgesia without intensifying motor and sympathetic block during spinal anesthesia. In the present study $25 \mu \mathrm{g}$ fentanyl along with bupivacaine was used as similar to the previous studies done. Singh et al showed that $25 \mu \mathrm{g}$ fentanyl prolongs duration of sensory analgesia without prolonging motor block or increased adverse effect. ${ }^{22}$

The technique to achieve unilateral distribution of spinal anaesthesia used in the present study has been discussed earlier in the studies done by Valanne et al, Enk et, Casati et al. ${ }^{7,13,16}$ The present study was conducted to evaluate the efficacy of low dose of bupivacaine alone and in combination with fentanyl by evaluating the onset and duration of sensory and motor blockade.

Onset of sensory block in our study was $6.73 \pm 1.52 \mathrm{~min}$ and $6.17 \pm 1.44 \mathrm{~min}$ in Group B and Group BF respectively. Highest level of sensory block in Group B was T10 (T8-T12) and in BF Group was T10 (T8-T12). Time to achieve this highest level was $15.83 \pm 2.4 \mathrm{~min}$ and $15.43 \pm 2.26$ min respectively. Our result correlates with the other studies. In study by Singh et al, highest level achieved in Group B and BF was T8 and T7 respectively and time to achieve it was 7.1 and 7.5 min respectively. ${ }^{22}$ In study done by Korhonen et al, sensory block reached was T11 in BF group and T10 in B group. Time to reach peak level was 14-17 minutes, while Ben-David et al achieved T7 and T8 level in 11 and 10 minutes in B and BF group respectively. This shows that addition of 
fentanyl has no effect on onset of bupivacaine induced spinal block and achieving higher peak level as well as time to achieve peak level. ${ }^{1,23}$

In our study, 2 segment regression was 61 vs. 90 minutes and regression to L3 segment was 128 vs. 152 minutes in $\mathrm{B}$ and $\mathrm{BF}$ group respectively and these findings were found to be very highly significant $(p=0.000)$ and proved that fentanyl prolongs the sensory blockade. Our results are comparable to other results of Ben-David et al. ${ }^{23}$
Table 8: Patients and surgeons satisfaction.

\begin{tabular}{|lll|}
\hline & $\begin{array}{l}\text { Group B } \\
(\mathbf{n = 3 0})\end{array}$ & $\begin{array}{l}\text { Group BF } \\
(\mathbf{n = 3 0})\end{array}$ \\
\hline Patient 's satisfaction & $100 \%$ & $100 \%$ \\
\hline Surgeon's satisfaction & $100 \%$ & $100 \%$ \\
\hline
\end{tabular}

Table 9: Comparison of complications and side effects between the two groups.

\begin{tabular}{|llllllll|}
\hline \multirow{2}{*}{ Side effects } & Group B $(\mathbf{n}=\mathbf{3 0})$ & \multicolumn{2}{l}{ Group BF $(\mathbf{n = 3 0}$} & Total & No. & $\mathbf{\%}$ & p value \\
\cline { 2 - 7 } & $\mathbf{N o}$ & $\mathbf{\%}$ & $\mathbf{N o}$ & $\mathbf{\%}$ & $\mathbf{N}$ & - \\
\hline Hypotension & 0 & 0 & 0 & 0 & 0 & 0 & 1.000 \\
\hline Bradycardia & 1 & 3.3 & 1 & 3.3 & 2 & 3.3 & - \\
\hline Respiratory depression & 0 & 0 & 0 & 0 & 0 & 0 & $0.038^{*}$ \\
\hline Pruritus & 0 & 0 & 4 & 13.3 & 4 & 6.7 & - \\
\hline Sedation & 0 & 0 & 0 & 0 & 0 & 0 & - \\
\hline Nausea and vomiting & 0 & 0 & 0 & 0 & 0 & 0 & - \\
\hline Urinary retention & 0 & 0 & 0 & 0 & 0 & 0 & - \\
\hline PDPH & 0 & 0 & 0 & 0 & 0 & 0 & - \\
\hline TNS & 0 & 0 & 0 & 0 & 0 & 0 & - \\
\hline
\end{tabular}

Table 10: Comparison of PACU time, fast tracking.

\begin{tabular}{|llll|}
\hline & Group B $(\mathbf{n}=\mathbf{3 0})$ & Group BF $(\mathbf{n = 3 0})$ & p value \\
\hline Fast Tracking (No of patients) & $14(47 \%)$ & $6(20 \%)$ & 0.028 \\
\hline PACU (No of patients) & $16(53 \%)$ & $24(80 \%)$ & 0.000 \\
\hline PACU Time (Min) & $15.69 \pm 3.85$ & $30.13 \pm 10.79 *$ & \\
\hline
\end{tabular}

Table 11: Comparison of duration of analgesia.

\begin{tabular}{|llll|}
\hline & $\begin{array}{l}\text { Group B } \\
(\mathbf{n}=\mathbf{3 0})\end{array}$ & $\begin{array}{l}\text { Group BF } \\
(\mathbf{n}=\mathbf{3 0})\end{array}$ & $\begin{array}{l}\mathbf{p} \\
\text { value }\end{array}$ \\
\hline $\begin{array}{l}\text { Duration of } \\
\text { analgesia(min) }\end{array}$ & $162.97 \pm 9.26$ & $266.37 \pm 9.47$ & 0.000 \\
\hline
\end{tabular}

In this study motor blockade was assessed by Bromage score and found score of 0/1/2/3:0/3/7/20 in Group B and 0/1/2/3:0/2/13/15 in Group BF i.e. $27(80 \%)$ patients in Group B and $28(82 \%)$ patients in Group BF of Grade $\geq 2$. Three patients in Group B and two patients in Group BF had motor block of 1 , but none of the five patients complained of discomfort during surgery and surgeons also did not face any problem intraoperatively. So in both the groups motor blockade was equal and adequate for the surgeries to be performed. In our study, time to complete recovery of motor blockade was $107 \pm 9.22$ and $109 \pm 6.38$ minutes in Group B and Group BF respectively. Our results are similar with the results of study done by Singh et al and Ben-David et al. ${ }^{22,23}$
In the present study sensory and motor blockade in nonoperated limb was also noted. Three patients in Group BF and one patient in Group B developed sensory block above L1 in the non-operated limb. So in our study, we were able to obtain unilateral sensory blockade, $98.33 \%$ in Group B and 95\% in Group BF patients. These observations are consistent with the findings of Barghi et al. ${ }^{11}$ Hence we can conclude that lower doses of bupivacaine without fentanyl lead to more unilateral distribution of sensory and motor block when needle gauge, speed of injection and lateral decubitus position time kept constant. In our study, none of the patients of either group had inadequate analgesia or required general anaesthesia for failed block that are similar to the results by Barghi et al and Singh et al.

Patients and surgeons satisfaction during intraoperative was also analysed in the present study. Most of the patients felt complete absence of sensation while very few had sensation of motion only. None of the patients in both the groups had inadequate or failed spinal 
anaesthesia, so as to require IV supplementary analgesics or general anaesthesia to complete the surgery. None of the surgeons felt difficulty in performing surgery in both groups.

No failed block or inadequate analgesia was seen in our study. This may be due to high anaesthetic concentration were achieved near nerve roots of operated limb in unilateral spinal block which could account for slow regression of sensory block due to reduced surface available for absorption and elimination of local anaesthetic from subarachnoid space. The quality of sensory block was improved by the addition of fentanyl in one group.

On comparing hemodynamics in our study, incidence of hypotension, respiratory depression was not observed in any of the groups. Only two patients, one in each group had bradycardia which responded to i.v. atropine. Thus hemodynamics was stable in both the groups. These findings are similar to the observations of Ben-David et al, Varrassi et al, Biswas et al also found notable hemodynamic stability that seems unaffected by the addition fentanyl. ${ }^{23,28,30}$

Sedation score was similar in both the groups and most of the patients were awake and calm and did not require any intraoperative sedation. This suggests the safety of this technique even in high risk patients .It also has the advantage that it avoids the need for intense monitoring of patient in immediate postoperative period in a busy PACU.

We observed pruritus as the most common side effect of intrathecal fentanyl in four patients $(13.3 \%)$ of Group BF although it was mild and did not require any treatment. The results are similar to the findings of Singh et al, found pruritus (10\%) and Khanna et al has found pruritus in $20 \%$ of patients with $25 \mu \mathrm{g}$ fentanyl. ${ }^{22,31}$ Nausea, vomiting was not observed in this study and supported by similar studies by Singh et al and Manullang et al. ${ }^{22,32}$ The postoperative analgesia was also significantly higher ( $p=0.000)$ in Group BF $(266.37 \pm 9.47$ minutes) than in Group B (162.97 \pm 9.26 minutes) and the results were correlated with finding of Korhonen et al and Khanna et al. ${ }^{1,31}$

In this study 14 patients (47\%) in group B and $6(20 \%)$ patients in group BF were fast tracked in general ward. Sixteen patients $(53 \%)$ and $24(80 \%)$ patients in group B and group BF respectively needed to be shifted to PACU and they remained there for $15.69 \pm 3.85$ and $30.13 \pm 10.79$ minutes respectively. In general ward they remained for observation for at least $24 \mathrm{hrs}$ postoperatively for surgical purpose and not discharged home. These results were comparable to with the results by Korhonen. ${ }^{1}$ It was observed that both groups in our study had complete motor recovery at the same time. Fentanyl prolonged sensory block but not motor block.
In our patients no influence of intrathecal dose of fentanyl and bupivacaine in delaying return of bladder function was noted and these reports are similar to earlier studies of Ben-David et al. ${ }^{23,33,34}$ None of our patients developed PDPH or TNS which is consistent with study by Korhonen et al. ${ }^{1}$ There was longer duration of postoperative analgesia in fentanyl-bupivacaine groups; this also increases with the increasing dose of bupivacaine. However, motor recovery was not affected by the addition of fentanyl.

\section{CONCLUSION}

Our study demonstrates that small dose of bupivacaine in unilateral spinal anaesthesia is adequate to provide optimal anaesthesia without hemodynamic compromise for short procedure on lower limb, but addition of fentanyl $(25 \mu \mathrm{g})$ improves duration of analgesia intraoperatively and postoperatively, thus making it more reliable. It doesn't intensify or prolong motor block. It doesn't produce any adverse side effects except for mild pruritus. It doesn't significantly prolong recovery or reduce fast tracking. Thus unilateral spinal anaesthesia with $5 \mathrm{mg}$ hyperbaric bupivacaine with $25 \mu \mathrm{g}$ fentanyl is a better choice than $5 \mathrm{mg}$ hyperbaric bupivacaine alone in short procedure of lower limb in orthopaedic surgery.

Funding: No funding sources

Conflict of interest: None declared

Ethical approval: The study was approved by the Institutional Ethics Committee

\section{REFERENCES}

1. Korhonen AM, Valanne J, Jokela R, Ravaska P, Korttila K. Intrathecal hyperbaric bupivacaine $3 \mathrm{mg}+$ fentanyl 10mg for outpatient knee arthroscopy with tourniquet. Acta Anaesthesiol Scand. 2003;47:342-6.

2. Hamp KF, Schnieder MC, Ummenhofer W, Drewe J. Transient neurologic symptoms after spinal anaesthesia. Anesth Analg. 1995;81:1148-53.

3. Poolock JE, Neal JM, Stephenson CA, Wiley CE. Prospective study of the incidence of transient radicular irritation in patients undergoing spinal anaesthesia. Anesthesiology. 1996;84:1361-7

4. Tarkkila P, Hubtala J, Tuominen M. Transient radicular irritation after spinal anaesthesia with hyperbaric $5 \%$ lignocaine. $\mathrm{Br} \mathrm{J}$ Anaesth. 1995;74:328-9

5. Sjostrom S, Blass J. Severe pain in both legs after spinal anaesthesia with hyperbaric 5\% lignocaine solution. Anaesthesia. 1994;49:700-2

6. Freedman JM, Li DK, Drasner K, Jaskela MC, Larsen B, Wi S. Transient neurologic symptoms after spinal anaesthesia: an epidemiologic study of 1863 patients. Anaesthesiology. 1998;89:633-41.

7. Valanne V, Korhonen A, Jokela R, Ravaska P, Korttila KK. Selective spinal anaesthesia: A comparison of hyperbaric bupivacaine $4 \mathrm{mg}$ versus 
6mg for outpatient knee arthroscopy. Anesth Analg. 2001;93:1377-9.

8. Tarkkila P, Hubtala J, Tuominen M. Home readiness after spinal anaesthesia with small doses of hyperbaric $0.5 \%$ bupivacaine. Anaesthesia. 1997;52:1157-60.

9. Casati A, Fanelli G, Cappelleri G, Borghi B, Cedrati V, Torri G. Low dose hyperbaric bupivacaine for unilateral spinal anaesthesia. Can J Anaesth. 1998;45(9):850-4.

10. Casati A, Fanelli G, Aldegheri G, Colnaghi E, Casaletti E, Cedrati V, et al. Frequency of hypotension during conventional or asymmetric hyperbaric spinal block. Reg Anesth Pain Med. 1999;24:214-9.

11. Borghi B, Stagni F, Bugamelli S, Paini MB, Nepoti ML, Montebugnoli $\mathrm{M}$, et al. Unilateral spinal block for outpatient knee arthroscopy: A dose finding study. J Clin Anesth. 2003;15:351-6.

12. Fanelli G, Borghi B, Casati A, Bertini L, Montebugnoli M, Torri G. Unilateral bupivacaine spinal anaesthesia for outpatient knee arthroscopy. Can J Anaesth. 2000;47(8):746-51.

13. Enk D. Unilateral spinal anaesthesia - gadget or tool? Current opinion. Anesthesiology. 1998;11:511-5.

14. Casati A, Fanelli G, Beccaria P, Aldegheri G, Berti $\mathrm{M}$, Senatore R, et al. Block distribution and cardiovascular effects of unilateral spinal anaesthesia by 5\% hyperbaric bupivacaine: A clinical comparison with bilateral spinal block. Minerva Anesthesiol. 1998;64:307-12

15. Kuusneimi KS, Pihlajamaki KK, Irjala JK, Jaakkola PW, Pitkänen MT, Korkeila JE. Restricted spinal anaesthesia for ambulatory surgery: A pilot study. Eur J Anaesthesiol. 1999;16:2-6.

16. Casati A, Fanelli G, Cappelleri G, Aldegheri G, Leoni A, Casaletti E, et al. Effects of spinal needle type on lateral distribution of $0.5 \%$ hyperbaric bupivacaine. Anesthesiology. 1998;87:355-9.

17. Casati A, Fanelli G, Cappelleri G, Leoni A, Berti M, Aldegheri G. Does speed of intrathecal injection affect the distribution of $0.5 \%$ hyperbaric bupivacaine. Br J Anaesth. 1998;81:355-7.

18. Casati A, Fanelli G, Cappelleri G, Aldegheri G, Berti M, Senatore R, et al. Effects of speed of intrathecal injection in unilateral spinal block by $1 \%$ hyperbaric bupivacaine: A randomized, double blind study. Minervo Anesthesiol. 1999;65:5-10.

19. Serpell MG, Gray WM. Flow dynamics through spinal needles. Anaesthesia. 1997;52:229-36.

20. Belzarena SD. Clinical effects of intrathecally administered fentanyl in patients undergoing caesarean section. Anesth Analg. 1992;74:653-7.

21. Butterworth JF IV, Strichartz GR. Molecular mechanisms of local anaesthesia: A review. Anesthesiology. 1900;72:711-34.
22. Singh H, Yang J, Thornton K, Giesecke AH. Intrathecal fentanyl prolongs sensory bupivacaine block. Can J Anesth. 1995;42(11):987-91.

23. Ben-David B, Solomon E, Admoni H, Goldik Z. Intrathecal fentanyl with small-dose dilute bupivacaine: better anaesthesia without prolonging recovery. Anesth Analg. 1997;85:560-5.

24. Enk D, Prien T, Van Aken H, Mertes N, Meyer J, Brüssel T. Success rate of unilateral spinal anesthesia is dependent on injection flow. Reg Anesth Pain Med. 2001;26:420-7.

25. Fanelli G, Borghi B, Casati A, Bertini L, Montebugnoli M, Torri G. Unilateral bupivacaine spinal anesthesia for outpatient knee arthroscopy. Italian Study Group on Unilateral Spinal Anesthesia. Can J Anaesth. 2000;47:746-51.

26. Kuusniemi KS, Pihlajamäki KK, Pitkänen MT. A low dose of plain or hyperbaric bupivacaine for unilateral spinal anesthesia. RegAnesth Pain Med. 2000;25:605-10.

27. Breebart M, Vercauteren M, Hoffman V, Adriaeensen $\mathrm{H}$. Urinary bladder scanning after daycase arthroscopy under spinal anaesthesia: comparison between lidocaine, ropivacaine and levobupivacaine. Br J Anesth. 2003;90:309-15.

28. Reuben SS, Donn SM, Sullivan P. An intrathecal fentanyl dose - response study in lower extremity revascularization procedures. Anesthesiology. 1994;81(6):1371-5.

29. Varassi G, Celleno D, Capogna G. Ventilatory effects of subarachnoid fentanyl in elderly. Anaesthesia. 1992;47:558-62.

30. Biswas BN, Rudra A, Bose B. Intrathecal fentanyl with hyperbaric bupivacaine improves analgesia during caesarean delivery and in early postoperative period. Indian J Anaesth. 2002;46(6):469-72.

31. Khanna M, Singh I. Comparative evaluation of bupivacaine plain versus bupivacaine with fentanyl in spinal anaesthesia in geriatric patients. Indian $\mathrm{J}$ Anaesth. 2002;46(3):199-203.

32. Manullang TR, Viscomi CM, Pau NL. Intrathecal fentanyl is superior to intravenous ondansetron for prevention of perioperative nausea during caesarean delivery with spinal anaesthesia. Anesth Analg 2000; 90: 1162-6.

33. Marshall SI, Chung F. Discharge criteria and complications after ambulatory surgery. Anaesth Analg. 1999;88:508.

34. Mulroy M. Effect of short acting spinal and epidural anaesthesia on voiding. Anaesthesiology. 2002;97:315-9.

Cite this article as: Jaiswal VS, Thakare DW Comparison of unilateral spinal anaesthesia using low dose bupivacaine with or without fentanyl in lower limb surgery. Int J Basic Clin Pharmacol 2016;5:1752-8. 